\title{
AUTHOR CORRECTION \\ Correction to: Progression-free survival at 24 months and subsequent survival of patients with extranodal NK/T-cell lymphoma: a China Lymphoma Collaborative Group (CLCG) study
}

Yong Yang, Ying Wang, Xin Liu, Xia He, Li-Ling Zhang, Gang Wu, Bao-Lin Qu, Li-Ting Qian, Xiao-Rong Hou, Fu-Quan Zhang, Xue-Ying Qiao, Hua Wang, Gao-Feng Li, Yuan Zhu, Jian-Zhong Cao, Jun-Xin Wu, Tao Wu, Su-Yu Zhu, Mei Shi, Li-Ming Xu (D), Hang Su, Yu-Qin Song, Jun Zhu, Yu-Jing Zhang, Hui-Qiang Huang, Chen Hu D, Shu-Nan Qi (D) and Ye-Xiong Li (DD

(c) The Author(s), under exclusive licence to Springer Nature Limited 2021

Leukemia (2021) 35:2736-2737; https://doi.org/10.1038/s41375-021-01371-6 


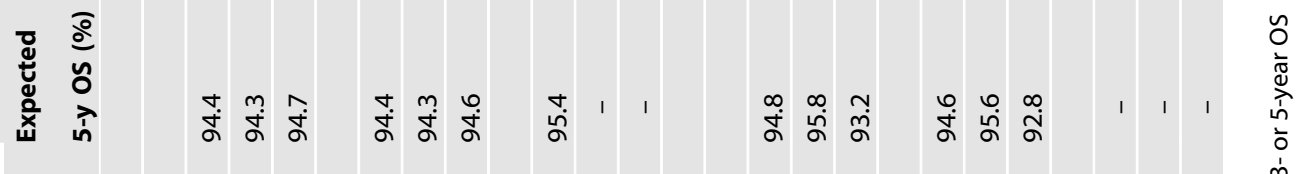

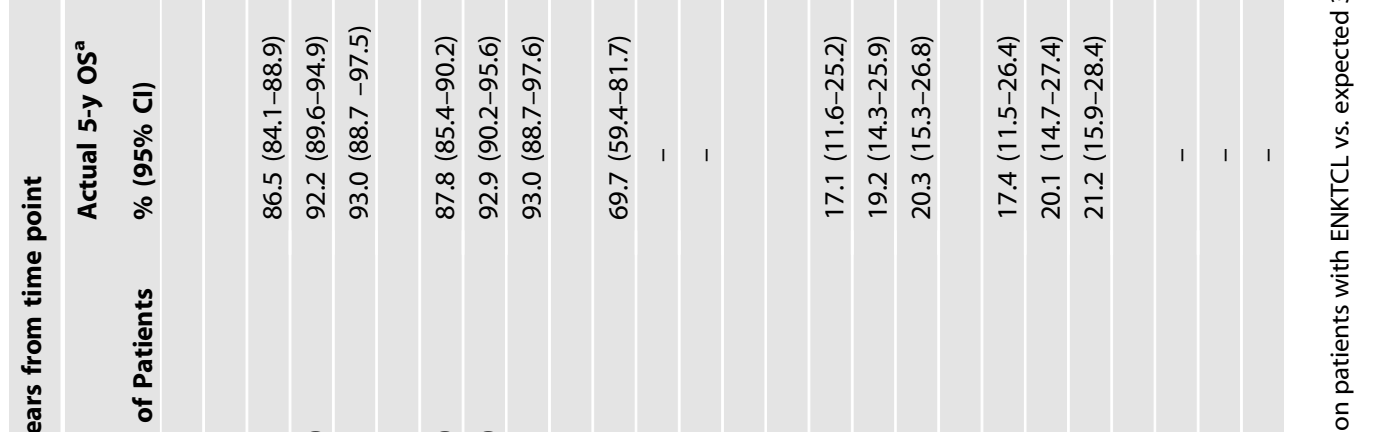

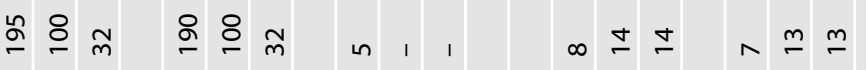

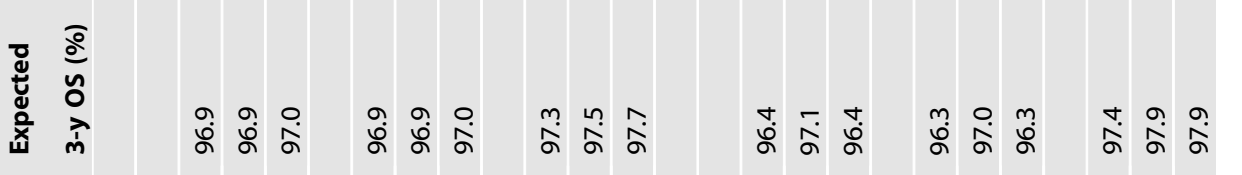

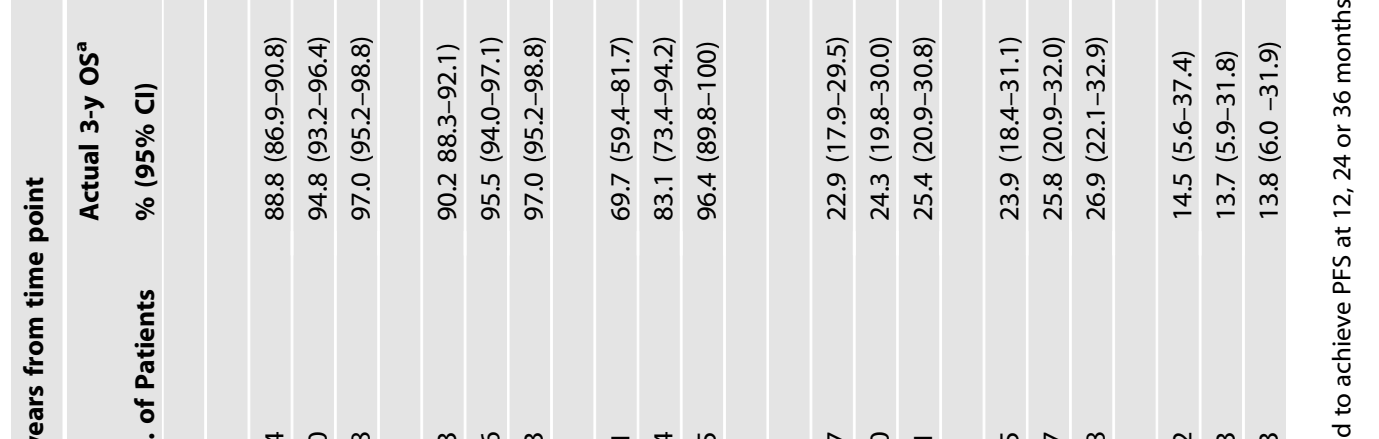

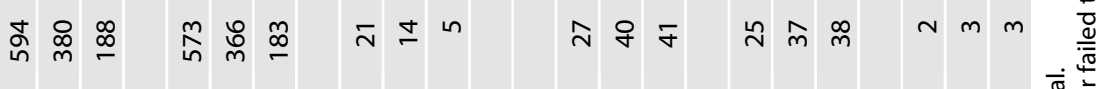

$\stackrel{\dot{m}}{\frac{\dot{m}}{8}}$

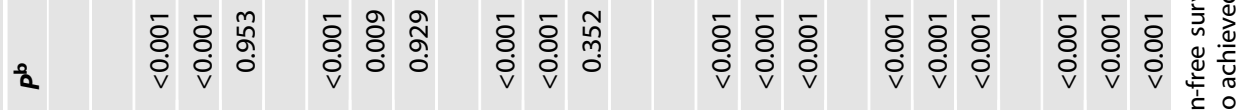

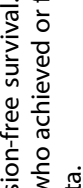

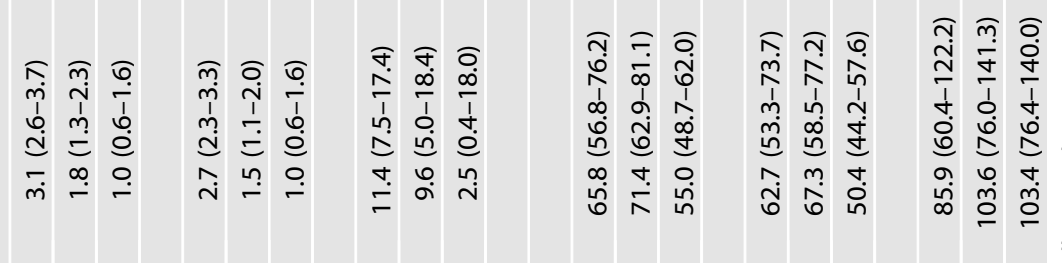

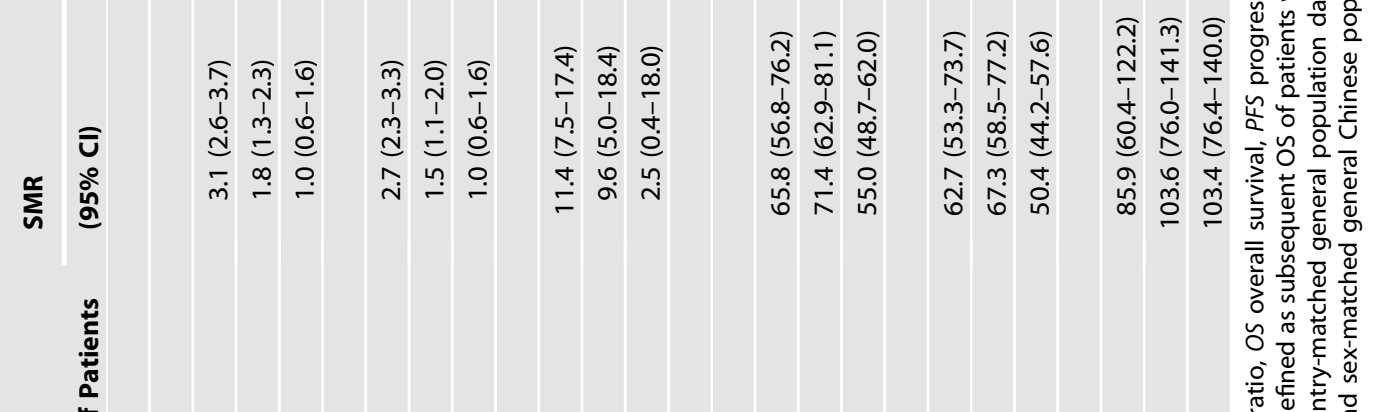

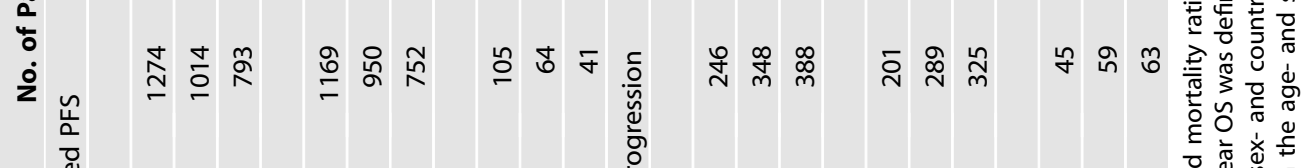

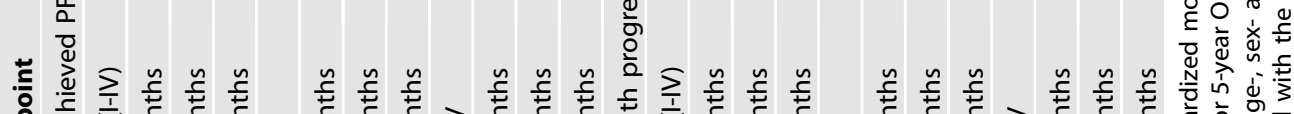

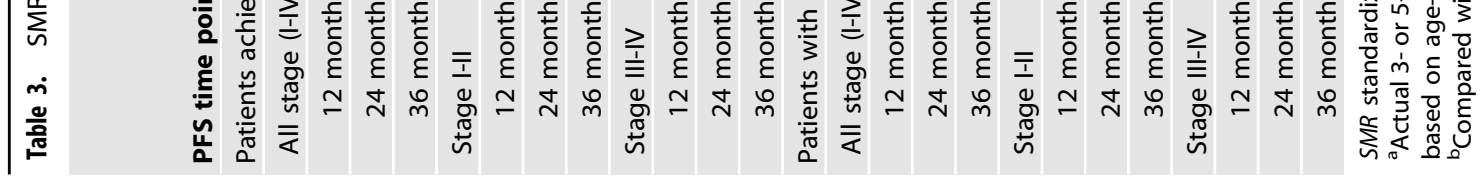

